\title{
Комплекс геофизических, геоморфологических и сейсмотектонических исследований в изучении постледниковой активности западных Хибин (на примере ущелья Аку-Аку)
}

\author{
Королева А.О. ${ }^{1,2}$, Родкин М.В. ${ }^{3}$ \\ ${ }^{1}$ Институт физики Земли им О.Ю. Шмидта РАН, Москва, kaо@ifz.ru \\ ${ }^{2}$ Институт географии РАН, Москва \\ ${ }^{3}$ Институт теории прогноза землетрясений и математической геофизики PAH, Москва, rodkin@mitp.ru
}

\begin{abstract}
Аннотация. Хибинский массив привлекает внимание исследователей большим количеством интересных объектов, расположенных в его пределах. В работе представлены результаты геофизических, геоморфологических и палеосейсмологических исследований, проведенных в районе ущелья Аку-Аку на юго-западе Хибинского массива. Поиск сейсмонарушений проводился как непосредственно в самом ущелье (на его дне и бортах), так и с воздуха при помощи квадрокоптера DJI Mavic Pro, что позволило выделить некоторые геоморфологические особенности данного объекта не очевидные при наблюдении на земной поверхности. Ущелье Аку-Аку, наравне с другими сейсмотектоническими объектами, является свидетельствами постледниковой сейсмотектонической активности данного региона. В работах авторы опираются на предшествующие исследования коллег по оценке возраста отложений, лихенометрические наблюдения, а также на признаки сейсморазрывов. Проведенные работы позволили определить природу происхождения данного объекта и отнести его к постледниковым сейсмотектоническим объектам.
\end{abstract}

Ключевые слова: геофизические исследования, геоморфология, квадрокоптер, палеосейсмодислокации, Кольский полуостров, очаговая зона палеоземлетрясений.

\section{A complex of geophysical, geomorphological and seismotectonic research in the study of postglacial activity of the western Khibiny (on the example of the Aku-Aku gorge)}

\author{
Koroleva A.O. ${ }^{1,2}$, Rodkin M.V. ${ }^{3}$ \\ ${ }^{1}$ Schmidt Institute of Physics of the Earth RAS, Moscow, kao@ifz.ru \\ ${ }^{2}$ Institute of Geography RAS, Moscow \\ ${ }^{3}$ Institute of Earthquake Prediction Theory and Mathematical Geophysics RAS, Moscow, rodkin@mitp.ru
}

\begin{abstract}
The Khibiny massif attracts the attention of researchers with many interesting objects located within its boundaries. The paper presents the results of geophysical, geomorphological and paleoseismological studies carried out in the area of the Aku-Aku gorge in the south-west of the Khibiny massif. The search for seismic disturbances was carried out both directly in the gorge itself (on its bottom and sides), and from the air using a DJI Mavic Pro quadcopter, which made it possible to highlight some geomorphological features of this object that were not obvious in detection from the earth's surface. The Aku-Aku gorge is included in the group of objects studied by the authors in the south-west of the Khibiny massif, along with other seismotectonic objects, which are evidence of postglacial seismotectonic activity in this region. In their works, the authors rely on previous research by colleagues to assess the age of deposits, lichenometric observations, as well as signs of seismic disturbances. The work carried out made it possible to determine the nature of the origin of this object and attribute it to postglacial seismotectonic objects.

Key words:_geophysical research, geomorphology, quadrocopter, paleoseismic dislocations, Kola Peninsula, focal zone of paleoearthquakes.
\end{abstract}

\section{Введение}

Современная сейсмическая активность Кольского полуострова, как известно, достаточно слабая. Оценка сейсмической опасности региона основана на данных современного сейсмического мониторинга. Однако, за последние десятилетия различными группами исследователей были собраны и опубликованы важные материалы, которые дают основание говорить о высокой сейсмотектонической палеоактивности в этом регионе (Никонов и др., 2019). Тектоническая структура Кольского региона обусловлена системой разнопорядковых блоков, которые подняты на разную высоту по мо- 
лодым и возрожденным древним разломам (Николаева и др., 2018). Существует целый ряд представительных и ярко выраженных объектов, которые, при помощи различных методов, следует изучать более детально, с целью уточнения и дополнения уже имеющихся данных по изучаемому району.

Уже не первый год авторы занимаются детальным исследованием ущелья Аку-Аку, расположенном в 2.5 км на северо-восток от станции Нефелиновые пески на восточном берегу озера Большая Имандра. Этот объект представляет большой интерес, ведь наряду с другими сейсмотектоническими объектами входит в систему сейсмонарушений юго-западного сектора Хибинского массива, окруженного населенными пунктами, горнодобывающими предприятиями и энергетическими коммуникациями.

\section{Геоморфологические наблюдения}

Ущелье Аку-Аку имеет СВ-ЮЗ простирание, и протягивается на 5 км от долины реки Гольцовка до перевала «Звездочка». В районе озера Изумрудное ущелье меняет направление и визуально разделяется на две части: северную и южную. Северная часть ущелья (рис. 1 а) имеет узкое дно (20-50 м), крутые борта, наблюдается большое количество разновозрастных обвалов. Южная часть ущелья (рис. 1 б) имеет наиболее широкое дно (50-100 м). Борта ущелья осложнены обвалами (осыпями) с обеих сторон. Одной из самых крупных особенностей ущелья, которая, к тому же, прослеживается на всем его протяжении, являются отщеления массивных вертикальных глыб с восточного борта, сдвинувшихся на несколько метров ко дну ущелья (рис. 2). Примечательно, что подобные структуры обнаружены только на восточном борту, в то время, как на западном борту наблюдаются только обвалы и осыпи.
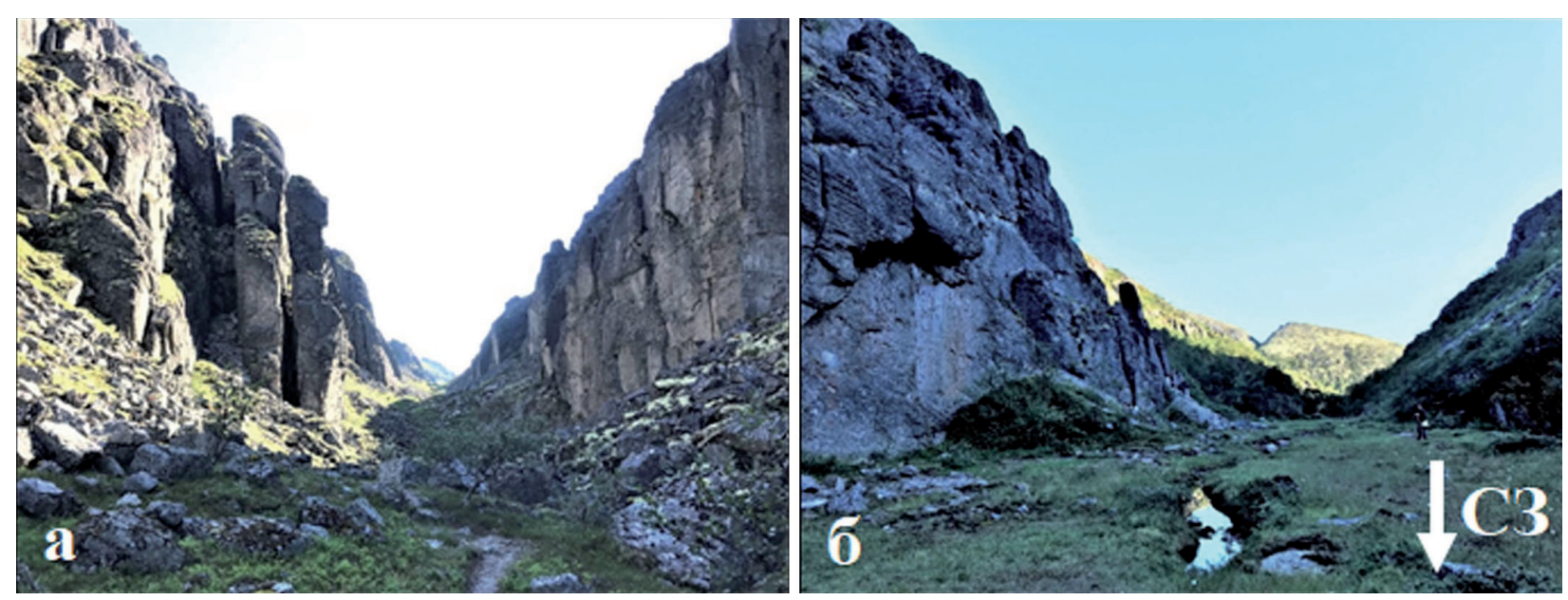

Рис. 1. Северная (а) и южная (б) части ущелья.

Fig. 1. Northern (a) and southern (b) parts of the gorge.

Геоморфологические исследования были дополнены фото- и видеосъемкой ущелья с воздуха квадрокоптером DJI Mavic Pro. Это позволило обнаружить различные структуры, не доступные для наблюдения с поверхности земли.

В районе озера Изумрудное, в месте «перегиба» ущелья, ручей впадает в долину водопадом, упирается в противоположный борт ущелья и поворачивает на $90^{\circ}$ на ЮЗ. Далее он протекает по долине ущелья до соединения с соседней подобной долиной перевала «Юмъекорр». В месте поворота ручья наблюдается взброшенная сухая долина, которая является логичным продолжением направления течения ручья. По геоморфологическим наблюдениям можно заключить, что ранее ручей протекал по этой субширотной долине (на рис. 2 показано голубым пунктиром) с выходом в оз. Имандра, а после взброса западного борта ущелья Аку-Аку ручей повернул на ЮЗ (на рис. 2 показано сплошной линией). Подобное предположение было подтверждено геофизическими данными. Ранее на данном объекте геофизических работ не проводилось. 


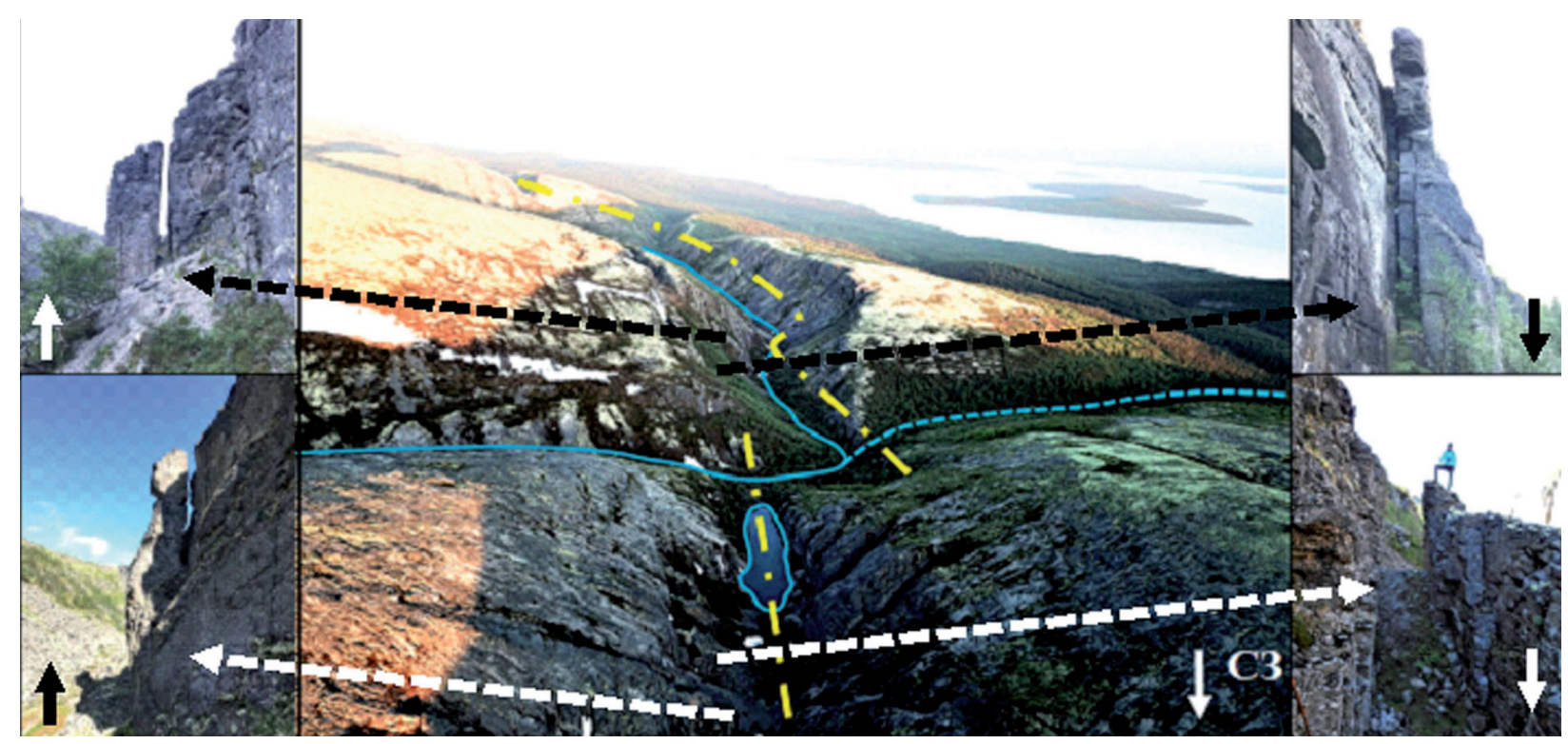

Рис. 2. Участок «перегиба» ущелья. На картинках изображены отщеления блоков с восточного борта ущелья. Стрелками показано направление на С3.

Fig. 2. The section of the «bend» of the gorge. The pictures show spalling of blocks from the eastern side of the gorge. Arrows show the direction to the NW.

\section{Геофизические исследования}

Исследования глубинных структур ущелья Аку-Аку были проведены электроразведочным методом ЗСБ (зондирование становлением поля в ближней зоне). Этот метод основывается на явлении электромагнитной индукции. В качестве источника электромагнитного поля используется незаземленная генераторная петля, по которой пропускают импульсный электрический ток. В моменты паузы в приемной петле регистрируется спад ЭДС, который характеризует разрез.

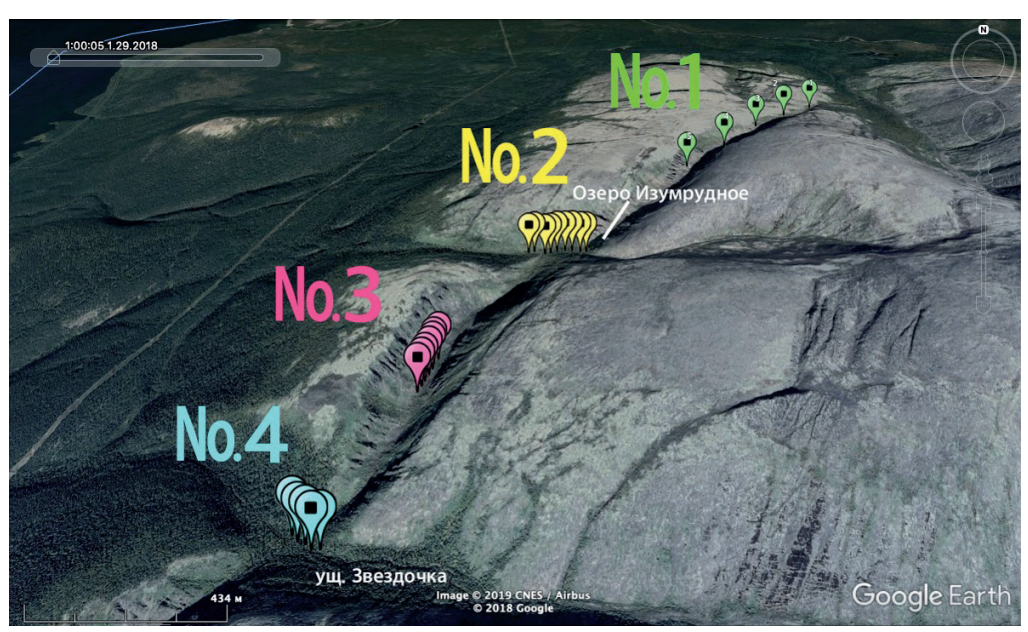

Рис. 3. Общий вид геофизических профилей.

Fig. 3. General view of geophysical profiles.

Измерения проводились по четырем профилям: двум поперечным к ущелью и двум продольным (рис. 3). Съемка велась прибором Tem-fast 48, с совмещенной генераторно-приемной петлей $25 \times 25$ м и током 1 A.

Определяющие условия работ в данном регионе - это высокие сопротивления пород и, как следствие, слабые сигналы в приемной антенне. При этом присутствует мощный эффект индуцированной поляризации, что отражается в виде отрицательных сигналов на кривых удельноэлектрического сопротивления (УЭС) (обозначены квадратами на рис. 4). В целом, данные такого характера слабо информативны и не дают представления о проводимости разреза. В экспериментальных измерениях на сплошном кристаллическом массиве кривые сопротивления полностью состояли из отрицательных сигналов.

Кривые УЭС на профилях № 2, 3, 4 стабильно демонстрируют зону проводимости в центральной части ущелья. На поперечных профилях № 2 и № 4 проводник выделяется в центральных пикетах (рис. 4 б, в), в то время как на крайних пикетах (которые были установлены на бортах ущелья, а 


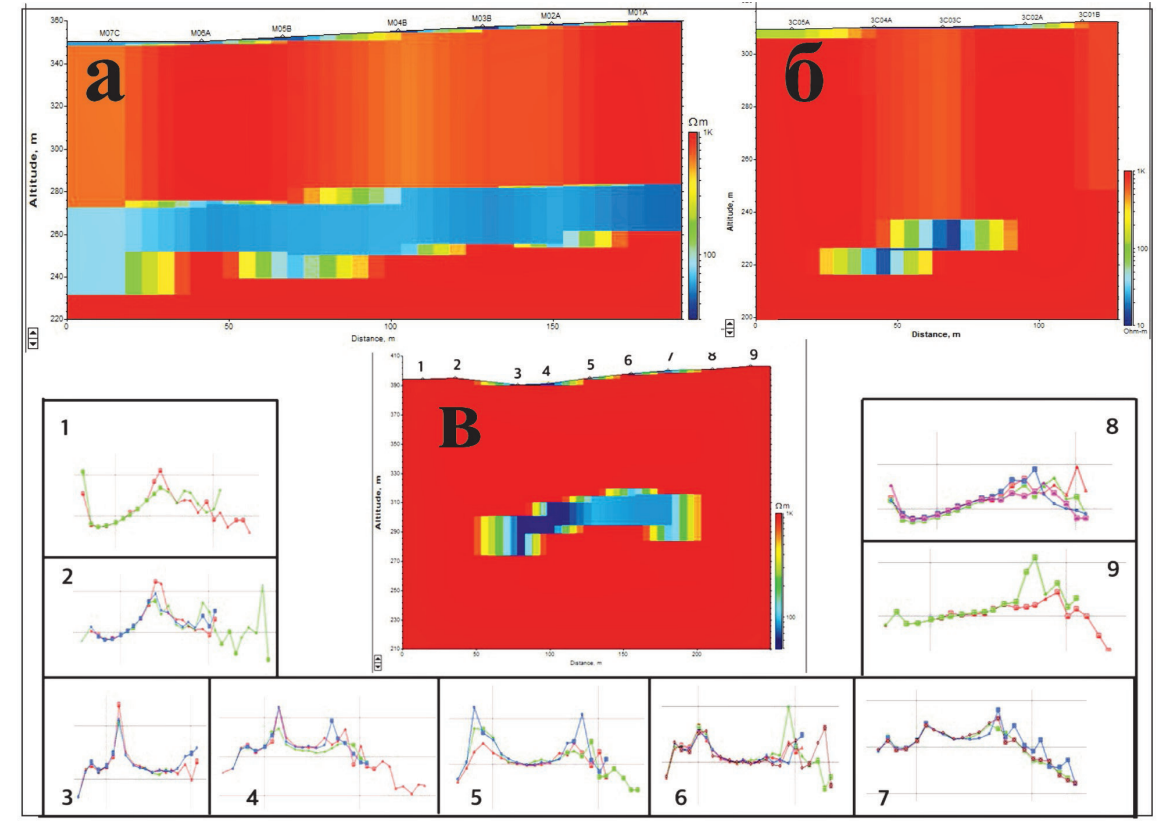

Рис. 4. Геоэлектрические разрезы по продольному профилю № 3 (а) и по поперечным профилям № 4 (б) и № 2 (в). Также на рисунке приведены кривые УЭС по профилю №2 по 8-ми пикетам.

Fig. 4. Geoelectric joins along the longitudinal profile № 3 (a) and along the transverse profiles № 4 (b) and № 2 (c). The figure also shows the resistivity curves along profile № 2 at 8 pickets.

не на его дне) - он не наблюдается. На разрезе по продольному профилю № 3 проводящий слой прослеживается на всех пикетах (рис. 4 a), что говорит о том, что он тянется по ущелью от места впадения ручья в ущелье Аку-Аку и до слияния его с ущельем около перевала «Звездочка».

А вот результаты обработки данных, полученных при работе на профиле № 1, показали, что все кривые профиля состоят из отрицательных сигналов. Это значит, что признаки проводимости тут отсутствуют, как и отсутствует деятельность ручья. Любопытно интерпретировать проводящий слой, как водонасыщенный осадок, нанесенный ручьем в ущелье, который прослеживается на всей южной части, широкой и заболоченной, а в северной, где ущелье сухое и более узкое, такого слоя не наблюдается.

Моделирование и интерпретация разрезов проводились в программе Tem-Reseacher. Подбор кривых показал, что проводящий объект залегает на глубине 80 м и имеет мощность до 20 м. Возможно, вышележащие породы также имеют низкое сопротивление, однако эффект поляризации является большой помехой на ранних временах и скрывает картину реальной проводимости.

\section{Слещения скальных отдельностей}

Специальное внимание в полевых работах было уделено поиску и выделению признаков сейсмического воздействия (выбивания блоков, отщеления, сдвиги, зеркала скольжения, разрывы). На прилегающем к ущелью с запада отроге с ровной вершинной поверхностью был проведен поиск и измерение величин блоковых смещений. Всего выявлено 34 примера смещения камней; по этим данным была построена многолепестковая гистограмма азимутов смещений (рис. 5), где выделяются три основные системы (I1, I2, I3), полученные по методу (Родкин и др., 2012).

Системы I1, I2 более широкие и предположительно более древние. Обращает внимание отсутствие в системе I1 симметричных основному максимуму смещений в направлении северо-востока. Можно предположить, что такая ситуация связана с направлением движения ледника последней стадии оледенения. А именно, на завершающей стадии уже не покровного, а горного оледенения Хибин, имело место очевидное сползание ледника вниз по долинам рек. Такой ледник уносил с собой все плохо сцепленные скальные блоки. Соответственно, при послеледниковом сейсмическом импульсе I1 уже не было скальных отдельностей, пригодных для смещений вниз по долине в 
северо-восточных азимутах. В пользу большей древности системы I1 свидетельствует также относительно более широкий разброс направлений отброса камней и большая выраженность максимума (можно предположить, что более ранние постледниковые землетрясения были и более сильными). Во всяком случае, скорость гляциоизостатического подъема территории Кольского полуострова демонстрирует сильное затухание со временем.

Система I3 имеет наиболее узкие лепестки максимумов распределения (рис. 5), и может поэтому полагаться предположительно наиболее молодой (смещения камней не были осложнены повторными перемещениями). Исходя из ширины максимумов, можно предположить, что системы I1, I2 более древние (I1 самая древняя), а система I3 самая молодая.
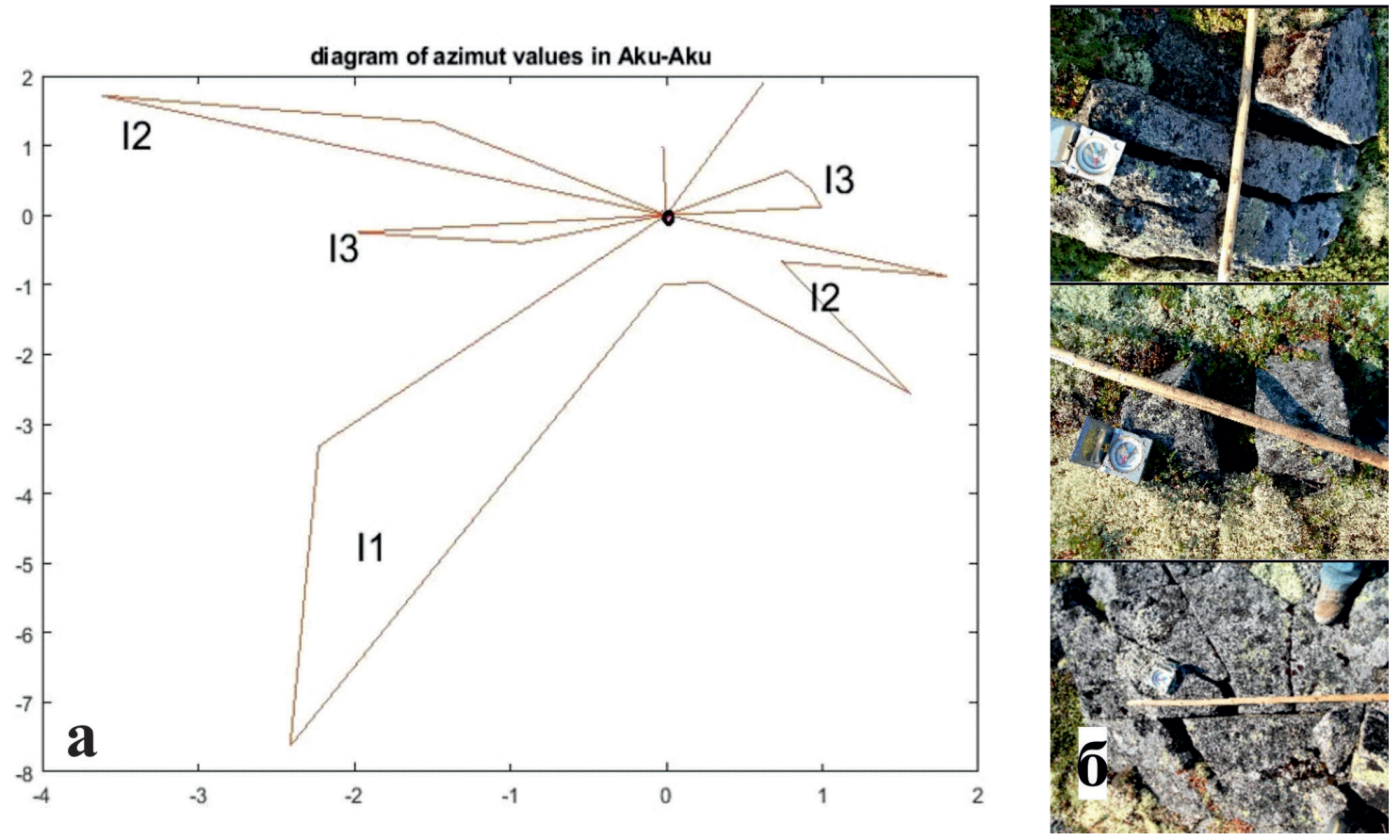

Рис. 5. а - диаграмма распределения азимутов смещений (указаны системы направлений азимутов I1, I2, I3) б - примеры блоковых смещений.

Fig. 5. a - diagram of the distribution of azimuths of displacements (systems of directions of azimuths I1, I2, I3 are indicated) $b$ - examples of block displacements.

\section{Лихенометрические исследования}

Также авторами работы были проведены лихенометрические наблюдения (рис. 6 б). Для максимальных размеров диаметров лишайника Phizocarpon geographicum для района ущелья Аку-Аку был получен 131 замер; кроме этого наблюдалось большое число скальных поверхностей без следов лишайников или с очень малыми (менее 1 мм) их размерами. Проведенные исследования позволили построить гистограмму полученных размеров лишайника, на которой отчетливо выделяются 3 достаточно четких максимума со значениями диаметров $\mathrm{D}=27.42$ и 50 мм (рис. 6 a). По преимущественным размерам лишайников указать точное время событий не представляется возможным, учитывая разночтения в скорости роста лишайников по данным разных специалистов. Например, по данным ботанического сада-института КНЦ РАН средняя скорость роста лишайника Phizocarpon geographicum в условиях Хибин составляет $18 \pm 3$ мм за 100 лет. В то время как согласно приведенным в (Никонов и др., 1986) данным, скорость роста лишайника Phizocarpon geographicum неравномерна во времени. Требуется некоторый период для его заселения на новой скальной поверхности и начала развития, и имеет место замедление роста старых лишайников. Отсюда оценки времени обвала (раскрытия скальной поверхности) по формуле роста $18 \pm 3$ мм за 100 лет можно считать существенно заниженными для начального периода роста и для старых лишайников. 


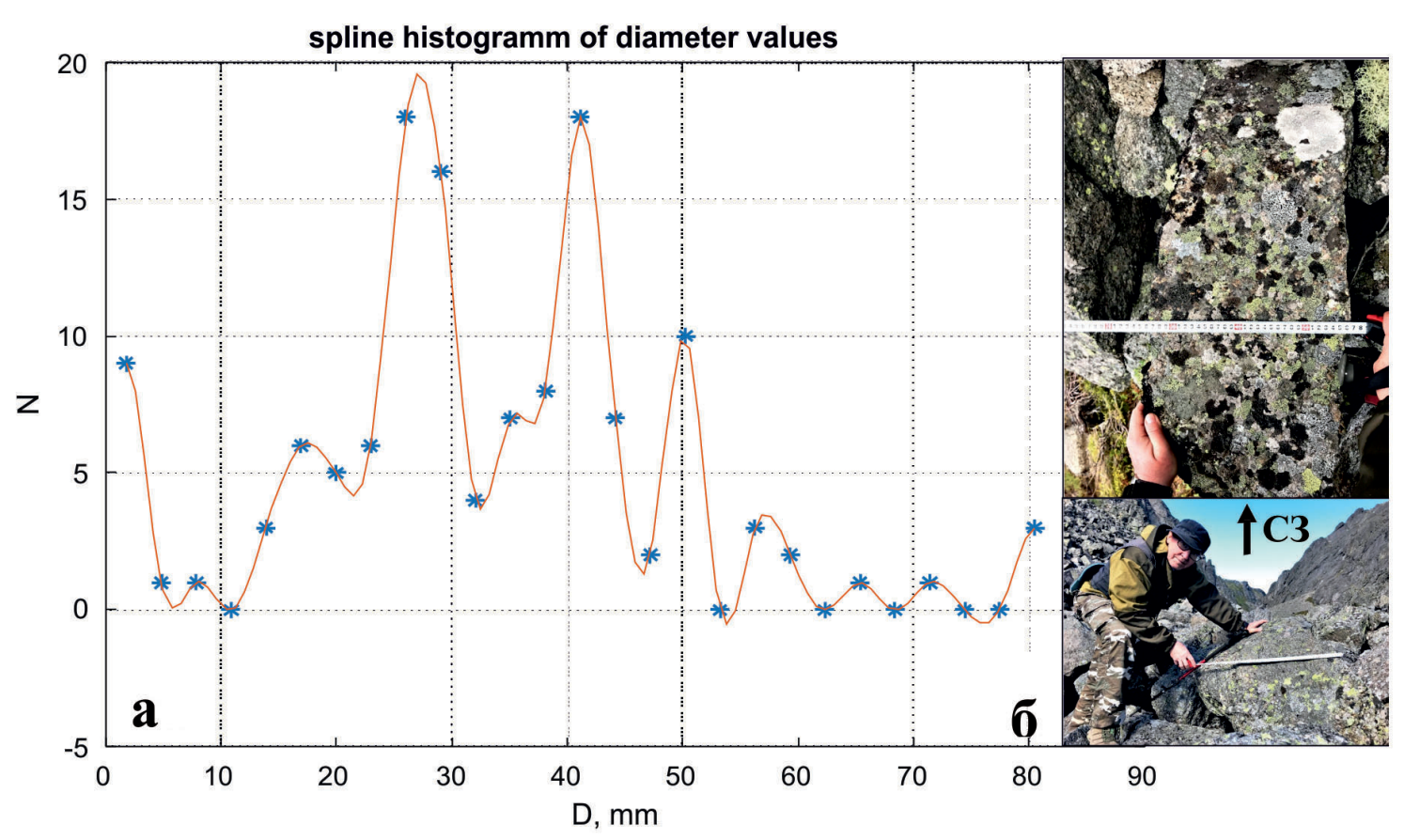

Рис. 6. а - гистограмма полученных размеров диаметров лишайников Phizocarpon geographicum; б - примеры глыб, покрытых лишайниками, расположенных в обвалах ущелья.

Fig. 6. a - histogram of measured diameters of Phizocarpon geographicum lichens; $b$ - examples of lichen-covered boulders located in the rockslides of the gorge.

Однако, хотелось бы отметить, что количество выделенных максимумов на гистограмме полученных размеров лишайников на рисунке 6а совпадает с числом преимущественных направлений смещений скальных блоков на рисунке 5. На данный момент результаты носят предварительный анализ. Радиоуглеродных определений не проводилось.

\section{Выводы}

Исследования, проведенные в районе ущелья Аку-Аку, позволили уточнить и дополнить имеющиеся сведения о данном объекте, а также опробовать геофизическое электроразведочное оборудование в нелегких условиях непроводящих горных пород. Полученные данные позволили выделить проводящую глубинную структуру, характерную только для южной части ущелья, а также обнаружить три характерных предположительно сейсмогенных азимута смещения скальных блоков и разделить их на три сейсмических события, произошедших в районе ущелья в постледниковое время. Также были проведены лихенометрические наблюдения, первичные результаты которых опубликованы в работе (Королева и др., 2019). В комплексе полученные данные свидетельствуют о высокой послеледниковой сейсмотектонической активности данного региона. Объект Аку-Аку подлежит дальнейшим исследованиям и детальной проработке.

Представляется возможным предположить, что районы голоценового оледенения являются относительно специфическими районами, где современная и палеосейсмичность резко различаются. Исходя из этого на данном этапе авторы не берутся утверждать, что довольно убедительные данные по сильной палеосейсмичности являются достаточным основанием для пересмотра современной сейсмической опасности несмотря на то, что по правилам МАгАтЭ они должны быть в полной мере приняты во внимание при оценке сейсмической опасности особо ответственных объектов (например, КоАЭС).

Работа выполнена в рамках тем госзаданий ИФЗ РАН № 0144-2019-0010 и ИГ РАН №01482019-0005. 


\section{Литература}

1. Королева А.О., Ивлева О.А., Родкин М.В., Викулина М.А. Свидетельства постледниковой сейсмотектонической активности западных Хибин // Современные методы оценки сейсмической опасности и прогноза землетрясений: тезисы докладов всероссийской научной конференции с международным участием. М. Изд-во: ИТПЗ РАН. 2019. С. 56-57

2. Николаева С.Б., Никонов А.А., Шварев С.В., Родкин М.В. Детальные палеосейсмогеологические исследования в бортовой зоне впадины оз. Имандра (Кольский регион): новые подходы и результаты // Геология и геофизика. 2018. Т. 59. № 6. С. 866-880. DOI: 10.15372/GiG20180608.

3. Никонов А.А., Шварев С.В., Николаева С.Б., Зыков Д.С., Флейфель Л.Д., Родкин М.В., Королева А.О. Три активные сейсмотектонические зоны высшего ранга на севере Европейской части России: прогрессрепорт // Проблемы тектоники континентов и океанов. Материалы LI тектонического совещания. T. 2. М. Изд-во: ГЕОС. 2019. С. 86-92.

4. Никонов А.А., Шебалина Т.Ю. Лихенометрический метод датирования сейсмодислокаций (методические аспекты и опыт использования в горах юга Средней Азии). М. Изд-во: Наука. 1986. 185 с.

5. Родкин М.В., Никонов А.А., Шварев С.В. Оценка величин сейсмических воздействий по нарушениям и смещениям в скальных массивах // Геодинамика и тектонофизика. 2012. Т. 3. С. $203-237$. DOI: $10.5800 /$ GT-2012-3-3-0072. 